\title{
REINVENTING HIGH SCHOOL: COMPETENCY-BASED MODEL FOR LEARNING IN THE 21ST CENTURY
}

Tahir M. Khan, Clinical Assistant Professor, Purdue University, tmkhan@purdue.edu Denise K. Whitford, Associate Professor, Purdue University, dwhitford@purdue.edu Lisa Lambert Snodgrass, Assistant Professor, Purdue University, 1snodgra@ purdue.edu Sunnie L. Watson, Associate Professor, Purdue University, sunnieleewatson@purdue.edu Lisa B. Bosman, Assistant Professor, Purdue University, lbosman@ purdue.edu

\begin{abstract}
Research shows that Black and Hispanic workers continue to be under-represented in the STEM (science, technology, engineering and mathematics) workforce. Purdue Polytechnic High School (PPHS) was established to achieve broader academic and workforce goals. PPHS fosters a sense of community for students by fostering diversity in teachers, focusing on project-based learning, and providing students with a constructive and collaborative space to explore their passions. To support career readiness, the school personalizes student learning and focuses on enhancing student problem-solving skills through a structured group engagement program called "passion projects". The school meets the academic requirements of the state while providing a meaningful and fun learning experience for students.
\end{abstract}

\section{Introduction}

The research focuses on the assessment and evaluation of a project-driven learning model at a STEM school in the midwestern United States. According to the Pew Research Center, Black and Hispanic workers remain underrepresented in the STEM workforce (Funk \& Parker, 2019). The PPHS's vision is twofold, 1) reinvent or reimagine high school, and 2) prepare students, especially underrepresented minorities, for STEM fields. The school uses a competency-based model to engage students in the classroom.

\section{Methods and Results}

Participants selected for this study are PPHS stakeholders, including seven parents, ten students, ten teachers, three board of directors, two industry partners, and one school administrator. The participants were interviewed to capture their perspectives on the least and most effective components, and the best practices associated with the model. A thematic analysis method was used to analyze the collected data. Primary research shows that the competency-based model supports students in learning and meets the academic requirements of the state while providing a meaningful and fun learning experience for students.

The PPHS students scored at or above the state average for passing rates in English, Math, and on both tests (Sorrells, 2019). The students reported the top three success factors, which are 1) teachers who are referred to as coaches, 2) school atmosphere that encourages them to manage and schedule schoolwork and extracurricular on their own, and 3) passion projects where teachers serve as facilitators.

\section{References}

Funk, C., \& Parker, K. (2019). Diversity in the stem workforce varies widely across jobs. Pew Research Center's Social \& Demographic Trends Project. Retrieved from https://www.pewresearch.org/socialtrends/2018/01/09/diversity-in-the-stem-workforce-varies-widely-across-jobs/

Sorrells, A. (2019). How one school is building a STEM pipeline for minority students with a direct pathway to college. EducationNC. Retrieved from https://www.ednc.org/how-one-school-is-building-a-stem-pipelinefor-minority-students-with-a-direct-pathway-to-college/ 